\title{
Habitat overlap between sympatric European hares (Lepus europaeus) and Eastern cottontails (Sylvilagus floridanus) in northern Italy
}

\author{
Anna Vidus-Rosin • Alberto Meriggi • Elisa Cardarelli • \\ Sara Serrano-Perez • Maria-Chiara Mariani • \\ Chiara Corradelli • Annalisa Barba
}

Received: 1 December 2009 / Accepted: 22 July 2010 /Published online: 9 November 2010

(C) Mammal Research Institute, Polish Academy of Sciences, Białowieża, Poland 2010

\begin{abstract}
In northern Italy, the range of the Eastern cottontail (Sylvilagus floridanus) largely overlaps with that of the native European hare (Lepus europaeus) on the Po Plain. Both species appear to have similar habitat requirements. We studied habitat selection by hares and cottontails during feeding activity from September 2006 to August 2007 in two areas where they occur alone (allopatry) and in one area where they occur together (sympatry). The three areas were basically similar, so that shifts in habitat use observed in sympatry should reflect the response to interspecific competition. Habitat selection was examined at micro- and macro-habitat levels throughout seasons. Habitat breadth of both species followed the change of resource availability through seasons in allopatry as well as in sympatry. No shifts in habitat use were evident at macrohabitat level, even during autumn which was the limiting season. Exploitation of shared habitats by the two species seems to be promoted by differential micro-habitat use within macro-habitat types. Cottontails used woods with dense understory in greater proportion than hares, and their present sites were concentrated within the maximum
\end{abstract}

Communicated by: Mathew W. Hayward

A. Vidus-Rosin $(\triangle) \cdot$ A. Meriggi $\cdot$ E. Cardarelli $\cdot$ M.-C. Mariani $\cdot$

C. Corradelli $\cdot$ A. Barba

Department of Animal Biology, University of Pavia,

Via Ferrata 1,

27100 Pavia, Italy

e-mail: anna.vidus@unipv.it

S. Serrano-Perez

Departamento de Anatomia, Biologia Celular y Zoologia,

Facultad de Veterinaria, Universitad de Extremadura,

Avda. Universitad sn,

10071 Caceres, Spain distance of $20 \mathrm{~m}$ of the nearest shelter site. Hares were more likely than cottontails to exploit crops, and their sites were distributed even greater than $80 \mathrm{~m}$ away from permanent cover patches. The habitat heterogeneity of agricultural ecosystems within the sympatry range could buffer the negative effects of external factors (climate, human disturbance and predation) on hares, and enhance the chances of exploitation of shared habitats by both species.

Keywords Sylvilagus floridanus $\cdot$ Lepus europaeus . Habitat breadth · Habitat selection · Sympatry .

Northern Italy

\section{Introduction}

The European hare (Lepus europaeus) is common in arable farmlands throughout Europe; however, the species underwent a decrease in abundance in the 1960s onward that has been documented in several European countries (MitchellJones et al. 1999; Smith et al. 2004, 2005; Central Italy, Santilli and Galardi 2006). The ultimate cause of the decline of hare numbers has been attributed to habitat heterogeneity occurring in different agro-ecosystems because of the adoption of modern agricultural practices (Vaughan et al. 2003; Smith et al. 2004; Reichlin et al. 2006; Pépin and Angibault 2007).

The European hare is widespread in Italy, with the exception of the two major islands, but its populations are limited by habitat change, overhunting and restocking with allochthonous hares (Meriggi and Alieri 1989; Meriggi and Verri 1990; Meriggi et al. 2001). The Eastern cottontail (Sylvilagus floridanus) was successfully introduced in northern Italy by several illegal releases from the 
end of the $1960 \mathrm{~s}$ onwards with the intention of increasing the potential for small game harvesting (Meriggi 2001; Spagnesi 2002; Vidus-Rosin et al. 2008). Eastern cottontails are currently naturalised in most of northern Italy and expanding along the rivers of the Po Plain. On the Po Plain, the range of the Eastern cottontail overlaps to a large extent with that of the native European hare. Both species seem to have similar habitat requirements, because the former prefers to settle in agriculturaldominated landscapes characterised by good habitat diversity, and the latter reaches its highest densities in arable farmlands where traditional agricultural practices still persist (Meriggi and Alieri 1989; Meriggi and Verri 1990; Silvano et al. 2000; Meriggi 2001; Meriggi et al. 2001; Vidus-Rosin et al. 2008). Locally, cottontails can reach greater densities than hares because of their smaller home range sizes and their better productivity; therefore the species may have greater dispersal and exploitation ability than the autochthonous hares (Swihart 1986; Vidus-Rosin et al. 2008).

In already simplified agro-ecosystems, the introduced species could compete with the native one by exploiting the same suitable habitats, thus reducing resource (food and cover) availability to hares. Generally, species of the same guild can occupy niches that overlap in terms of resources. For example, they can forage in similar habitats, use similar structural features to shelter or raise young, and have similar diets. In these cases, resource overlap alone does not necessarily predict the degree of exploitation competition, because species may partition resources spatially or temporally that lead to differences in habitat selection and may facilitate the coexistence between them even if resources are limited (Hurlbert 1978; Feinsinger et al. 1981; Pianka 1981; Fa et al. 1992; Morris 1996; Katona et al. 2004; Hayward and Kerley 2008; Hayward and Slotow 2009). One way to find evidence of exploitation competition between sympatric species is to compare the habitat use of a species in areas where it occurs alone (allopatry) with other areas where it occurs with another competing species (sympatry). If the two areas are basically similar, habitat shifts observed in sympatry should reflect the response to interspecific competition (Pianka 1981; Belovsky 1984; Bonino et al. 1997; Bonesi et al. 2004). We studied habitat selection by the European hare and the Eastern cottontail during feeding activity from September 2006 to August 2007 with the aims of: (1) quantifying the degree of habitat overlap between both species in sympatry, (2) evaluating any evidence of exploitation competition by comparing habitat use and breadth of both species in areas of allopatry and sympatry and (3) identifying the key factors allowing exploitation of shared habitats by the two species.

\section{Material and methods}

Study areas

The study was carried out in three areas (A: allopatry for hares, $4.3 \mathrm{~km}^{2}$; B: sympatry, $4.8 \mathrm{~km}^{2}$; C: allopatry for cottontails, $8.2 \mathrm{~km}^{2}$ ) located in the Province of Pavia, northern Italy (A: $45^{\circ} 05^{\prime} 09.40^{\prime \prime} \mathrm{N}, 9^{\circ} 13^{\prime} 22.94^{\prime \prime} \mathrm{E}$; B: $45^{\circ}$ $00^{\prime} 57.78^{\prime \prime} \mathrm{N}, 8^{\circ} 56^{\prime} 27.98^{\prime \prime} \mathrm{E}$; C: $45^{\circ} 04^{\prime} 25.84^{\prime \prime} \mathrm{N}, 9^{\circ} 00^{\prime}$ $\left.55.71^{\prime \prime} \mathrm{E}\right)$. The climate was continental-temperate; annual rainfall averaged $700 \mathrm{~mm}$ and was concentrated in spring and autumn. The yearly temperature averaged $12^{\circ} \mathrm{C}$ (January $1.0^{\circ} \mathrm{C}$ and July $22.5^{\circ} \mathrm{C}$ ). The ground was sandyclayey and crops were the most represented habitat type in all the areas (A: $82.6 \%$; B: $73.3 \%$; C: $53.7 \%$ ), especially winter cereals $(34.6 \%, 47.8 \%, 24.6 \%$, respectively). Spontaneous vegetation was present in woods, fallow fields and along hedgerows, field edges, basins and streams and it was more developed in area C $(26.9 \%)$ compared to area B (20.7\%) and area A (8.4\%). Anthropogenic-occupied areas (farmsteads, road networks and barren areas) occupied $9.0 \%$ of area $\mathrm{A}, 3.5 \%$ of area $\mathrm{B}$ and $7.4 \%$ of area $\mathrm{C}$. Arboriculture stands were present in area B $(2.5 \%)$ and in area $\mathrm{C}(12.0 \%)$. In our study areas, common overstory species included oaks (Quercus robur), white poplars (Populus alba), willows (Salix spp.), hornbeams (Carpinus betulus), elms (Ulmus campestris), cherries (Prunus avium) and locusts (Robinia pseudoacacia). Understory plants included hazels (Corylus avellana), hawthorns (Crategus spp.), brambles (Rubus spp.), elders (Sambucus spp.) and cornels (Cornus mas). Hare density, estimated by spotlight counts and distance sampling (Burnham et al. 1985; Buckland et al. 2001), averaged 71.7 individuals per square kilometre $(\mathrm{SE}=8.80)$ in area $\mathrm{A}$ and 35.9 individuals per square kilometre $(\mathrm{SE}=6.35)$ in area $\mathrm{B}$, whereas average cottontail densities were 115.1 individuals per square kilometre $(\mathrm{SE}=15.77)$ and 100.7 individuals per square kilometre $(\mathrm{SE}=13.35)$ in areas $\mathrm{C}$ and $\mathrm{B}$, respectively. The study was carried out for only 1 year, having ascertained land use in our study areas was constant during the last 5 years, and the weather was typical for the region throughout the study year.

\section{Methods}

We mapped vegetative cover types in each study area and in each season (autumn, September-November; winter, December-February; spring, March-May; summer, JuneAugust) by direct surveys and digitalized them using ArcView 3.2. We determined hare and cottontail habitat use by searching for the presence of faecal pellets in random plots (1-m radius) scattered in the study areas in each season (200 plots in area A, 150 in area B and 150 in 
area $\mathrm{C}$ ). This technique can be applied over a large area and provides data on seasonal habitat use patterns of hares and cottontails (Swihart and Yahner 1984; Litvaitis et al. 1985a, b; Langbein et al. 1999). Each plot was cleaned at the beginning of the survey and in each season pellets were removed from plots when found. Because cottontail and hare pellets were easily detected on the ground in all the seasons, this method provided an useful-inexpensive way to investigate sites used by the two lagomorph species within each habitat type. However, the survey effort to reach sampling plots and to search for pellets, within the 1-m radius area, closely depended on vegetation structure and density of each habitat.

We measured 11 macro-habitat variables (percentage of habitat types) within a $100-\mathrm{m}$ radius buffer from the plot centre and nine microhabitat variables within the 1-m radius plot (Appendix 1); moreover we calculated the shortest distance from each plot to the borders of patches of permanent cover (woods, arboriculture stands, fallow fields and edges). Plots were identified as 'used' by the presence of pellets and 'unused' by their absence.

\section{Statistical analyses}

\section{Macro-habitat use}

We identified six macro-habitat types and used them for the following analyses: crops (cultivated and ploughed fields), anthropogenic-occupied areas (farmsteads, villages, road networks, barren areas), alfalfa, permanent cover (woods, arboriculture stands, fallow fields) and edges. We calculated habitat breadth of hares and cottontails in each season using the Similarity Proportion Index proposed by Feinsinger et al. (1981):

$S P=1-0.5 \sum_{i=1}^{M}\left|p_{i}-q_{i}\right|$

where $M$ is the number of habitats in the study area, $p_{i}$ is the proportion of habitat $i$ used by the species and $q_{i}$ is the proportion of habitat $i$ available in the study area, with $\sum_{i=1}^{M} q_{i}=1$.

When the population utilises each resource in proportion to its abundance, $S P=1$. If the population uses the less available resources more intensively than the others, $S P=$ $\min \left(q_{i}\right)$.

We estimated seasonal habitat overlap between cottontails and hares in sympatry by Hurlbert's Index (Hurlbert 1978):

$L=\sum_{i=1}^{M} \frac{p_{H i} p_{C i}}{q_{i}}$

where now $P_{H i}$ is the proportion of habitat $i$ utilised by hares and $P_{C i}$ is the proportion of habitat $i$ utilised by cottontails. Hurlbert's overlap index is 1.0 when both species use each habitat in proportion to its abundance, 0 when the two species share no resources, and $>1.0$ when the two species both use certain habitats more intensively than others and the preferences of the two species for resources tends to coincide.

We used Manly's $\alpha$ Preference Index to evaluate seasonal habitat preference for the two species in allopatry, and to compare their habitat preference in sympatry (Manly et al. 1972; Chesson 1978; Manly et al. 1993; Krebs 1999):

$a_{i}=\frac{p_{i} / q_{i}}{\sum_{j=1}^{M}\left(p_{j} / q_{j}\right)}$

It is apparent from the formula that the $a_{i} \mathrm{~s}$ were normalised so that $\sum_{i=1}^{M} a_{i}=1$. When preference does not occur, $\alpha_{i}=1 / M$ for each $i=1, \ldots, M$. If $\alpha_{i}$ is greater than $1 / M$, then resource type $i$ is preferred. Conversely, if $\alpha_{i}$ is less than $1 / M$, resource type $i$ is avoided.

Regarding each index, we calculated the usage proportion of each habitat as the ratio between the number of positive plots found in each habitat and the total number of positive plots found, and the availability proportion of each habitat in the study areas as the ratio between the total number of plots in each habitat and the total number of plots scattered in each study area.

To test the reliability of the above indexes, we resampled the plots 1,000 times by the bootstrap method (Dixon 1993). Then we calculated the average values and the $95 \%$ confidence intervals of each index.

\section{Seasonal macro- and micro-habitat characteristics}

We compared macro- and micro-habitat variables measured in positive plots between hares and cottontails in sympatry using multivariate analysis of variance (MANOVA). The significance of each habitat variables (mean, \pm SE) was subsequently assessed by one-way ANOVA between positive plots of the two species in sympatry. Finally, we used the Kolmogorov-Smirnov Z Test with permutation to test for significant differences between the empirical distribution function of hare and cottontail positive plots in relation to the distance from the nearest permanent cover (i.e. woods, arboriculture stands, fallow fields, edges) (Norusis 1992, 1999).

\section{Results}

Macro-habitat use

Hare habitat breadth in allopatry area (area A) was similar to that in sympatry (area B) in every season, but in autumn 
it was slightly narrower in area A (Table 1). The same results were found for cottontails, but with the exception of the winter season where the species' habitat breadth was slightly narrower in the allopatry area (area C). Comparing the two species in allopatry, hare habitat breadth was broader than that of cottontails in winter and spring. Comparing the two species in sympatry, hare habitat breadth was broader than that of cottontails in autumn, winter and spring (Table 1). Habitat overlap between hares and cottontails in area B was similar in all the seasons and it was not significantly different from 1 (95\% confidence intervals; autumn $0.82-1.45$, winter $0.89-1.21$, spring $0.67-1.24$, summer 0.05-1.92).

In allopatry area (area A), hares avoided anthropogenicoccupied areas in all seasons; they used permanent cover and alfalfa significantly more than the other habitat types in autumn, and preferred only permanent cover in spring (Fig. 1). Cottontails, in allopatry area (area C) and in autumn, used permanent cover significantly more than the other habitat types, and the same was observed in winter and in spring with the exception of edges, whereas in summer the use of permanent cover was greater only than that of crops (Fig. 2). As far as the area of sympatry (area B) was concerned, hares used crops significantly more than cottontails in all seasons, whereas permanent cover was more used by cottontails in spring and anthropogenicoccupied areas in summer. Moreover, hares used crops, alfalfa and permanent cover more than anthropogenicoccupied areas in winter and summer; on the other hand, cottontails used alfalfa and permanent cover more than crops in autumn and winter, permanent cover more than crops in spring and permanent cover more than crops and anthropogenic-occupied areas in summer (Fig. 3a-d).

Macro- and micro-habitat characteristics

Considering the habitat characteristics of positive plots in sympatry area (area B), MANOVA provided significant results for species (Wilks' $\lambda=0.663, F_{(25,219)}=94.46, P<$ 0.001 ), seasons (Wilks' $\lambda=0.217, F_{(75,656)}=5.82, P<$

Table 1 Seasonal hare and cottontail habitat breadth ( $95 \%$ confidence intervals) in each area of allopatry (areas A and C) and sympatry (area B), 2006-2007, Province of Pavia, Italy

\begin{tabular}{lllll}
\hline Seasons & Area A & \multicolumn{2}{l}{ Area B } & Area C \\
\cline { 3 - 4 } & Hare & Hare & Cottontail & Cottontail \\
\hline Autumn & $0.57-0.79$ & $0.77-0.96$ & $0.46-0.76$ & $0.52-0.67$ \\
Winter & $0.84-0.93$ & $0.83-0.94$ & $0.64-0.86$ & $0.50-0.65$ \\
Spring & $0.82-0.93$ & $0.81-0.96$ & $0.46-0.70$ & $0.60-0.77$ \\
Summer & $0.73-0.89$ & $0.72-0.87$ & $0.69-0.89$ & $0.71-0.88$ \\
\hline
\end{tabular}

0.001), and for the interaction between the two factors (Wilks' $\lambda=0.608, F_{(75,656)}=1.58, P=0.002$ ). In particular, four habitat variables (height of bush, canopy cover, maize fields and vegetables) differed significantly between plots of the two species and between seasons $(P<0.001$ in all cases). In autumn, two habitat variables showed significant differences between hares and cottontails: litter cover and woods with greater means in cottontail plots. In winter, five micro- and five macro-habitat variables differed significantly between the two species: dead leaf cover, arboriculture stands, farmsteads and roads, woods and edges had greater means in cottontail plots, while winter cereals, distances from the nearest arboriculture stand, fallow fields, woods and hedgerows, had greater means in hare plots. In spring, eight micro- and four macro-habitat variables had different means between cottontail and hare plots: litter cover and its thickness, height of bush, canopy cover, fallow fields, woods and edges were greater in cottontail plots, while distances from the nearest arboriculture stand, fallow field, wood and non-herbaceous edge, and vegetables were greater in hare plots. In summer, five macro- and four micro-habitat variables differed between hare and cottontail plots: herbaceous cover, fallow fields, woods, edges and ponds and streams had greater means in cottontail plots, distances from the nearest, wood and nonherbaceous edge and winter cereals had greater means in hare plots (Table 2).

In spring and summer, we found significant differences between cottontail and hare distribution of positive plots in relation to the distance from the nearest patch of permanent cover $(Z=1.22, P=0.031$ and $Z=1.20, P=0.046$, respectively). In particular, we found $78.3 \%$ of cottontail plots and $53.3 \%$ for hares, in spring and $61.9 \%$ of cottontail plots and $40.5 \%$ of hare ones in summer within $40 \mathrm{~m}$ of the nearest patch of permanent cover.

\section{Discussion}

Several studies have demonstrated that coexistence is favoured when one of the competing species is a specialist behaving selectively, while the other is a generalist behaving opportunistically; when the specialist is also the dominant species, coexistence is predicted to be favoured in heterogeneous habitats where the subordinate generalist can segregate from the dominant specialist (Partridge 1978; Abramsky 1981; Pimm and Rosenzweig 1981; Rosenzweig 1981, 1991; Brown 1996; Morris 1996; Bonesi and Macdonald 2004; Bonesi et al. 2004; Manor and Saltz 2008).

Our results suggest that the European hare can be considered a generalist species, in terms of habitat requirements, with respect to the Eastern cottontail. The habitat 
Fig. 1 Average values of Manly's Index of habitat preference of hares in area A, 20062007, Province of Pavia, Italy

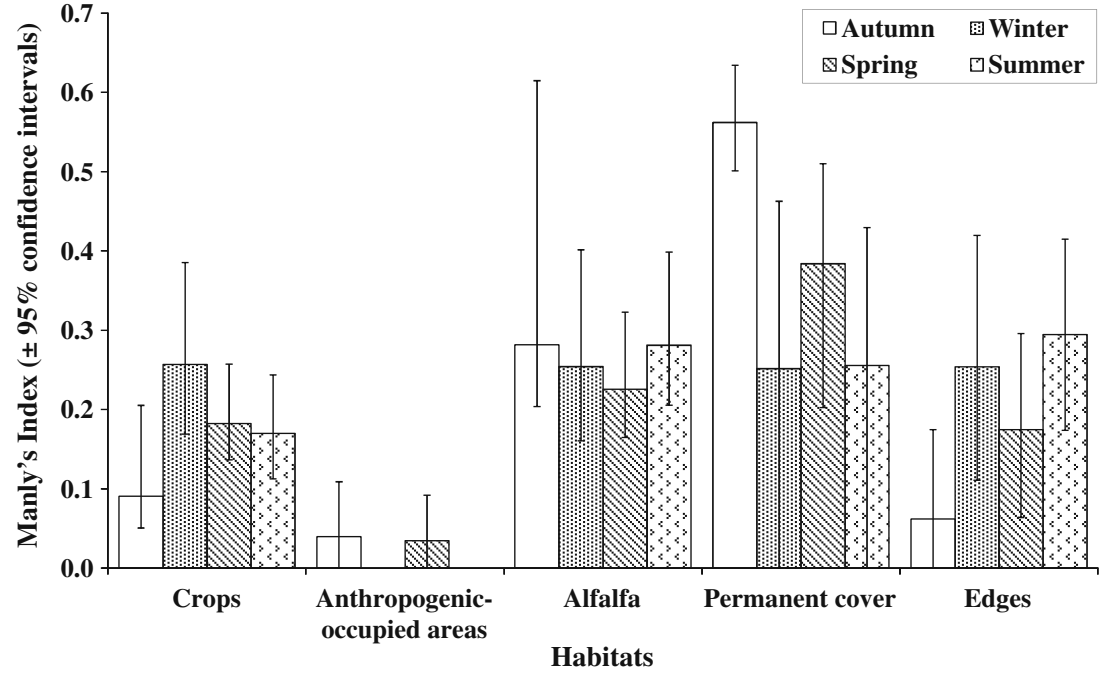

breadth of hares and cottontails across seasons likely reflected the change of the carrying capacity in the study areas. From the end of summer until late autumn, the sudden reduction of suitable foraging habitats of both species occurred because of crop harvesting, stubble tilling and field sowing. In winter, the availability of feeding resources improved because of the growth of winter cereals, and from spring to mid-summer it reached the maximum of coverage and height as most herbaceous crops were growing. The response of the two species to habitat changes was not similar in sympatry, and for each species between allopatry and sympatry. Indeed, at a local scale, habitat selection is a function of species habitat preference, population density and landscape heterogeneity (Fretwell and Lucas 1970; Rosenzweig 1981, 1991; Partridges 1978). In this study, hare habitat breadth was slightly narrower in allopatry than in sympatry during autumn, and this could be explained by taking into account the greater availability of alfalfa fields and of non-cropped habitats (edges and permanent cover) and the lower population density in the latter study area. Also habitat overlap between the two species in sympatry seems dependent on seasonal availability of suitable habitats, and it does not provide any evidence of potential competition between the two lagomorphs. Indeed, habitat preference of both species did not shift in sympatry with respect to allopatry. Permanent cover, alfalfa and crops were equally preferred by hares in allopatry as well as in sympatry. The species is known to feed on winter cereals and alfalfa during autumn and winter months, because they provide good quality food (Tapper and Barnes 1986; Reichlin et al. 2006), and on stubbles in summer because of the weeds which grow and dominated after harvesting (Reichlin et al. 2006). The avoidance of anthropogenic-occupied areas came out mostly in allopatry,
Fig. 2 Average values of Manly's Index of habitat preference of cottontails in area $\mathrm{C}$, 2006-2007, Province of Pavia, Italy

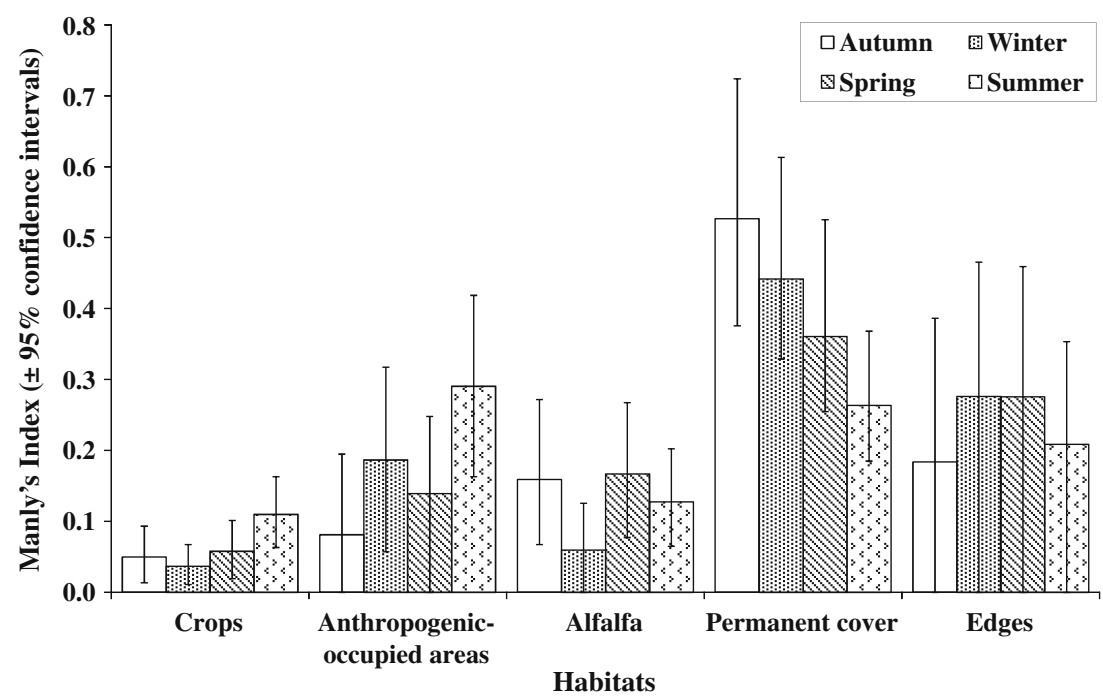



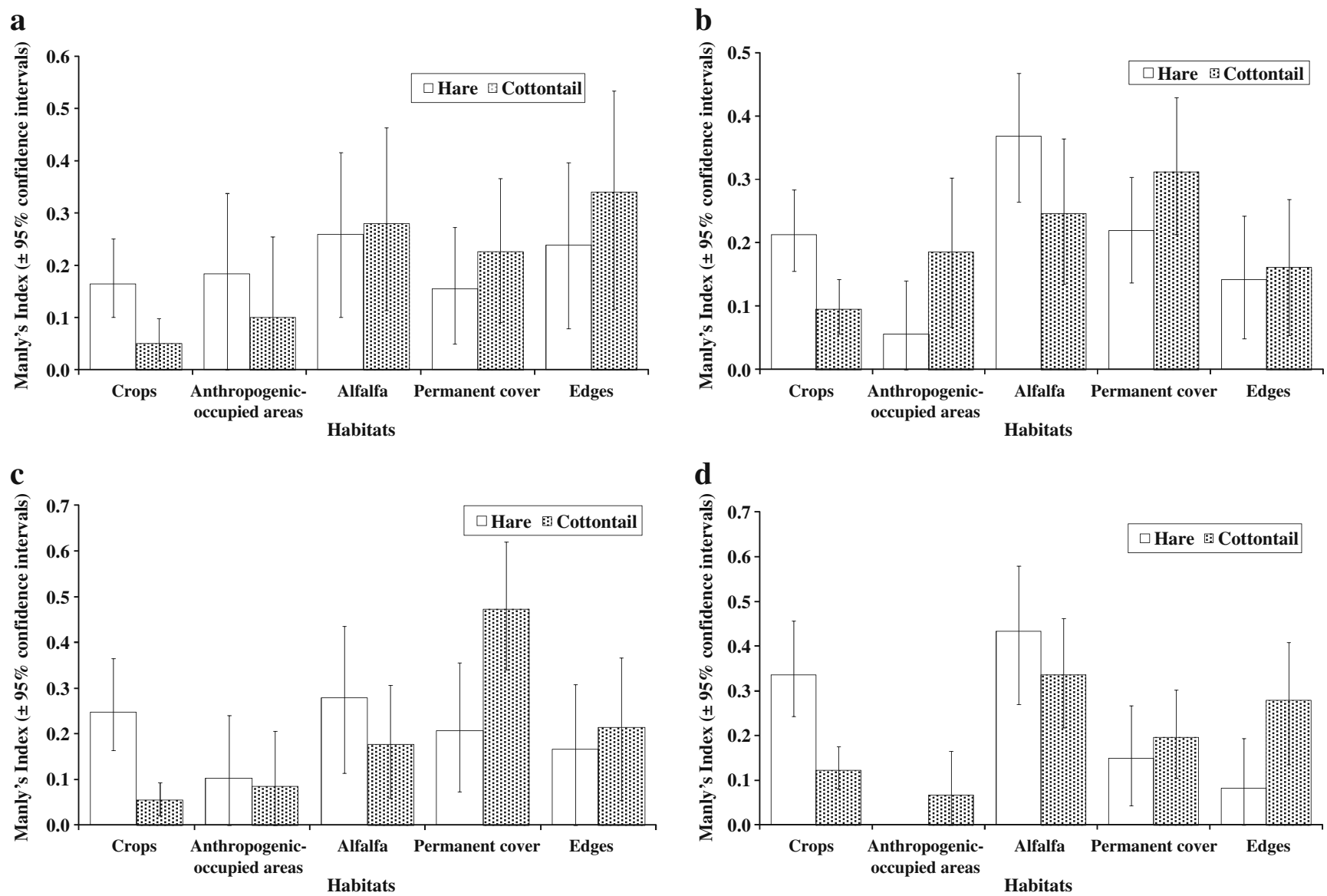

Fig. 3 Average values of Manly's Index of habitat preference of hares and cottontails in area B (a autumn, b winter, c spring, d summer, 20062007, Province of Pavia, Italy)

where villages and road networks were more developed than in the sympatric area; Roedenbeck and Voser (2008) identified the negative effect of villages and road networks on the spatial distribution of hares even in protected areas. Cottontails are also known to feed in association with permanent cover, mostly woods, hedgerows and arboriculture stands (Vance 1976; Swihart and Yahner 1982; Morgan and Gates 1983; Bond et al. 2001; Vidus-Rosin et al. 2008). Unlike hares, the avoidance by cottontails of crops underlines the relative importance of cropland in our study areas depending on abundance and availability of other herbaceous vegetation, such as alfalfa, edges, and of farmsteads that could provide food and good shelters to cottontails (piles, small buildings, machinery sheds; Swihart and Yahner 1982; Mankin and Warner 1999; Bond et al. 2002; Vidus-Rosin et al. 2008).

Even if the two species substantially share most habitats for feeding, habitat exploitation by them seems to be promoted by differential habitat use within macro-habitat types, as supported by different macro- and micro-habitat characteristics of their presence sites in sympatry. Studies on different taxa have noted that foraging behaviour is not only motivated by maximum acquisition of nutrients but also by predator avoidance, because whether a prey species (like lagomorphs) increases or decreases its vigilance rate, thereby sacrificing or increasing its foraging activity, may depend on how secure the species senses it is in its habitat structure (Barbour and Litvaitis 1993; Kie 1999; Smith and Litvaitis 2000; Bond et al. 2001). The two species exhibited contrasting dependence on cover for protection against predators during feeding due to their different anti-predator strategies: hares use long-distance running to escape from terrestrial predators while cottontails run away for short distances to shelter in the nearest dense cover (Cowan and Bell 1986; Fa et al. 1992; Althoff et al. 1997). In autumn, the substantial overlap in resource use between the two species at both the macro- and the micro-habitat level supports the evidence for the negative effect of resource availability reduction on hare and cottontail spatial distribution within simplified agro-ecosystems. However, cottontails used woods in greater proportion than hares, and within woodlots the species occupied also the central area where thick layers of plant litter were more developed. Woods with good understory represent a suitable habitat for 


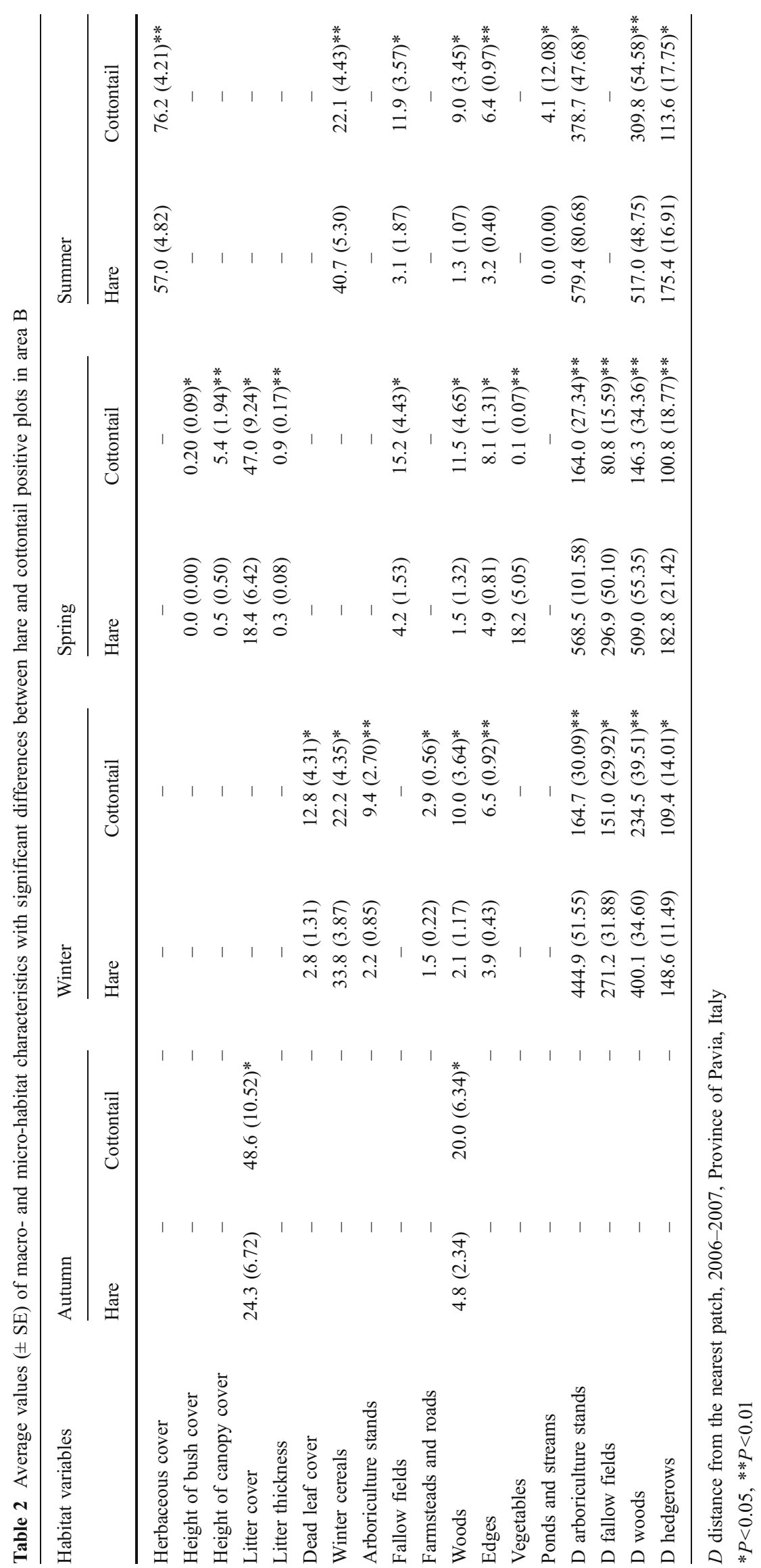


cottontails because they provide optimal cover from predators, abundant forage base and facilitate thermoregulation (Swihart and Yahner 1982; Althoff et al. 1997; Bond et al. 2001).

In general, it seems that hares were more likely than cottontails to exploit open habitats. Herbaceous-dominated habitats such as field margins, winter cereals and vegetables were suitable habitats for hares to forage both in spring and in summer, but their exploitation by cottontails was limited to mid-spring and the summer months (Mankin and Warner 1999; Bond et al. 2002). During the growing season, when the availability of suitable habitats for both lagomorph species is promoted by the growing of crops and spontaneous vegetation in the agricultural landscape, the two species segregate more intensively on the basis of their adaptability to exploit foraging habitats at different distances from the nearest patch of permanent cover. In our study area, cottontail sites were concentrated within the maximum distance of $20 \mathrm{~m}$ from the nearest shelter site.

In conclusion, it seems that European hare and Eastern cottontail may coexist in agricultural landscapes where there is enough habitat heterogeneity to be able to sustain populations of both species during the limiting season, and to maintain their differential perception of habitat structure promoting the segregation between them at least during feeding activity.

Acknowledgment We are grateful to Prof. L. Fattorini (University of Siena) for his statistical advice.

\section{Appendix 1}

Table 3 Habitat variables measured within 1-m radius plots and 100-m radius buffers

\begin{tabular}{ll}
\hline 1-m Radius plots & 100-m Radius buffer (\%) \\
\hline Herbaceous cover (\%) & Winter cereals \\
Height of herbaceous cover (cm) & Ploughed fields \\
Bush cover (\%) & Forage crops \\
Height of bush cover (m) & Arboriculture stands \\
Canopy cover (\%) & Fallow fields \\
Height of canopy cover (m) & Building areas \\
Dead leaf cover (\%) & Woods \\
Litter cover (\%) & Ponds and streams \\
Litter thickness (mm) & Row habitats \\
Distance from nearest arboriculture & Barren areas (gravel-pits \\
stand (m) & and gravel-rivershores) \\
Distance from nearest fallow field (m) & Maize fields \\
Distance from nearest wood (m) & \\
Distance from nearest hedgerow (m) & \\
Distance from nearest herbaceous edge (m) & \\
\hline
\end{tabular}

\section{References}

Abramsky Z (1981) Habitat relationships and competition in two Mediterranean Apodemus spp. Oikos 36:219-225. doi:10.2307/ 3544450

Althoff DP, Storm GL, Dewalle DR (1997) Daytime habitat selection by cottontails in central Pennsylvania. J Wildl Manag 61:450 459. doi: $10.2307 / 3802603$

Barbour MS, Litvaitis JA (1993) Niche dimensions of New England cottontails in relation to habitat patch size. Oecol 95:321-327. doi:10.1007/BF00320983

Belovsky GE (1984) Moose and snowshoe hare competition and a mechanistic explanation from foraging theory. Oecol 61:150159. doi:10.1007/BF00396753

Bond BT, Leopold BD, Burger LW Jr, Godwin KD (2001) Movements and home range dynamics of cottontail rabbits in Mississippi. J Wildl Manag 65:1004-1013. doi:10.2307/3803049

Bond BT, Burger LW Jr, Leopold BD, Jones JC, Godwin KD (2002) Habitat use by cottontail rabbits across multiple spatial scales in Mississippi. J Wildl Manag 66:1171-1178. doi:10.2307/3802950

Bonesi L, Macdonald DW (2004) Differential habitat use promotes sustainable coexistence between the specialist otter and the generalist mink. Oikos 106:509-519. doi:10.1111/j.00301299.2004.13034.x

Bonesi L, Chanin P, Macdonald DW (2004) Competition between Eurasian otter Luta lutra and American mink Mustela vison probed by niche shift. Oikos 106:19-26. doi:10.1111/j.00301299.2004.12763.x

Bonino N, Sbriller A, Manacorda MM, Larosa F (1997) Food partitioning between the mara (Dolichotius patagonum) and the introduced hare (Lepus europaeus) in the Monte Desert, Argentina. Stud Neotrop Fauna \& Environ 32:129-134

Brown JS (1996) Coevolution and community organization in three habitats. Oikos 75:193-206. doi:10.2307/3546243

Buckland ST, Anderson DR, Burnham KP, Laake JL, Thomas L (2001) Introduction to distance sampling: estimating abundance of biological populations. Oxford University press, Oxford

Burnham KP, Anderson DR, Laake JL (1985) Efficiency and bias in strip and line transect sampling. J Wildl Manag 49:1012-1018. doi: $10.2307 / 3801387$

Chesson PL (1978) Measuring preference in selective predation. Ecol 59:211-215. doi: $10.2307 / 1936364$

Cowan D, Bell DJ (1986) Leporid social behaviour and social organization. Mamm Rev 16:169-179. doi:10.1111/j.13652907.1986.tb00039.x

Dixon PM (1993) The bootstrap and the jackknife: describing the precision of ecological indices. In: Scheiner SM, Gurevitch J (eds) Design and analysis of ecological experiments. Chapman and Hall, New York, pp 290-318

Fa JA, Romero FJ, Paniagua LP (1992) Habitat use by parapatric rabbits in a Mexican high-altitude grassland system. J Anim Ecol 29:357-370. doi:10.2307/2404505

Feinsinger P, Spears EE, Poole RW (1981) A simple measure of niche breadth. Ecol 62:27-32. doi:10.2307/1936664

Fretwell SD, Lucas HL (1970) On the territorial behaviour and other factors influencing habitat distribution in birds. I Theoretical Development Acta Biotheor 19:16-36. doi:10.1007/BF01601953

Hayward MW, Kerley GIH (2008) Prey preferences and dietary overlap amongst Africa's large predators. South African J Wildl Res 38:93-108. doi:10.3957/0379-4369-38.2.93

Hayward MW, Slotow R (2009) Temporal partitioning of activity in large African carnivores: tests of multiple hypotheses. South African J Wildl Res 39:109-125. doi:10.3957/056.039.0207

Hurlbert ST (1978) The measurement of niche overlap and some relatives. Ecol 59:67-77. doi:10.2307/1936632 
Katona K, Biro Z, Hahn I, Kertesz M, Altbacker V (2004) Competition between European hare and European rabbit in a lowland area, Hungary: a long-term ecology study in the period of rabbit extinction. Folia Zool 53:255-268

Kie JG (1999) Optimal foraging and risk of predation: effects on behavior and social structure in ungulates. J Mamm 80:114 1129. doi: $10.2307 / 1383163$

Krebs CJ (1999) Ecological methodology, 2nd edn. Addison-Welsey, Canada

Langbein J, Hutchings MR, Harris S, Stoate C, Tapper SC, Wray S (1999) Techniques for assessing the abundance of Brown Hares Lepus europaeus. Mamm Rev 29:93-116. doi:10.1046/j.13652907.1999.00040.x

Litvaitis AJ, Sherburne JA, Bissonette JA (1985a) A comparison of methods used to examine snowshoe hare habitat use. J of Wildl Manag 49:693-695. doi:10.2307/3801696

Litvaitis AJ, Sherburne JA, Bissonette JA (1985b) Influence of understory characteristics on snowshoe hare habitat use and density. J Wildl Manag 49:866-873. doi:10.2307/3801359

Mankin PC, Warner RE (1999) Responses of Eastern cottontails to intensive row-crop farming. J Mamm 80:940-949. doi:10.2307/ 1383264

Manly BFJ, Miller P, Cook LM (1972) Analysis of a selective predation experiment. Am Nat 106:719-736. doi:10.1086/282808

Manly BFJ, McDonald LL, Thomas DL, McDonald TL, Erickson WP (1993) Resource selection by animals: statistical design and analysis for field studies. Kluwer Academic Publishers, Dordrecht

Manor R, Saltz D (2008) Conservation implications of competition between generalist and specialist rodents in Mediterranean afforested landscape. Biodivers Conserv 17:2513-2523. doi:10.1007/s10531-008-9397-1

Meriggi A (2001) Sylvilagus floridanus (Allen, 1890), Silvilago, Minilepre. In: Prigioni C, Cantini M, Zilio A (eds) Atlante dei mammiferi della Lombardia. Regione Lombardia e Università degli Studi di Pavia, Milano, pp 144-146

Meriggi A, Alieri R (1989) Factors affecting brown hare density in northern Italy. Ethol, Ecol and Evolut 1:255-264. doi:10.1080/ 08927014.1989 .9525515

Meriggi A, Verri A (1990) Population dynamics and habitat selection of European hare on poplar monocultures in northern Italy. Acta Theriol 35:69-76

Meriggi A, Ferloni M, Geremia R (2001) Studio sul successo dei ripopolamenti di Lepre. Università degli Studi di Pavia, Pavia

Mitchell-Jones AJ, Amori G, Bodganowicz W, Krystufek B, Reijnder PJK, Spitzenberger F, Stubbe M, Thissen JBM, Vohralik V, Zima J (1999) Atlas of European mammals. Academic, London

Morgan KA, Gates JE (1983) Use of forest edge and strip vegetation by eastern cottontails. J Wildl Manag 47:259-264. doi:10.2307/ 3808081

Morris DW (1996) Coexistence of specialist and generalist rodents via habitat selection. Ecol 77:2352-2364

Norusis MJ (1992) SPSS/PC+Base system user's guide, Vers. 5.0. SPSS Inc, Chicago

Norusis MJ (1999) SPSS/PC+advanced models, Vers. 9.0. SPSS Inc, Chicago

Partridge L (1978) Habitat selection. In: Krebs JR, Davies NB (eds) Behavioural ecology. An evolutionary approach. Blackwell Scientific Publications, Oxford, pp 351-376

Pépin D, Angibault JM (2007) Selection of resting sites by the European hare as related to habitat characteristics during agricultural changes. Eur J Wildl Res 53:183-189. doi:10.1007/ s10344-007-0087-1
Pianka ER (1981) Competition and niche theory. In: May RM (ed) Theoretical ecology. Principles and applications. Blackwell Scientific Publications, Oxford, pp 167-196

Pimm SL, Rosenzweig ML (1981) Competitors and habitat use. Oikos 37:1-6. doi:10.2307/3544067

Reichlin T, Klansek E, Hacklander K (2006) Diet selection by hares (Lepus europaeus) in arable land and its implications for habitat management. Eur J Wildl Res 52:109-118. doi:10.1007/s10344005-0013-3

Roedenbeck IA, Voser P (2008) Effects of roads on spatial distribution, abundance and mortality of brown hare (Lepus europaeus) in Switzerland. Eur J Wildl Res 54:425-437. doi:10.1007/s10344-007-0166-3

Rosenzweig ML (1981) A theory of habitat selection. Ecol 62:327335. doi:10.2307/1936707

Rosenzweig ML (1991) Habitat selection and population interactions: the search for mechanism. Am Nat 137:S5-S28. doi:10.1086/ 285137

Santilli F, Galardi L (2006) Factors affecting Brown hare (Lepus europaeus) hunting bags in Tuscany region (central Italy). Hystrix- It J Mammal 17:143-153

Silvano F, Acquarone C, Cucco M (2000) Distribution of the eastern cottontail Sylvilagus floridanus in the Province of Alessandria. Hystrix- It J Mammal 11:75-78

Smith DF, Litvaitis JA (2000) Foraging strategies of sympatric lagomorphs: implications for differential success in fragmented landscapes. Can J Zool 78:2134-2141. doi:10.1139/cjz-78-122134

Smith RK, Jennings NV, Robinson A, Harris S (2004) Conservation of European hares Lepus europaeus in Britain: is increasing habitat heterogeneity in farmland the answer? J Appl Ecol 41:1092 1102. doi:10.1111/j.0021-8901.2004.00976.x

Smith RK, Jennings NV, Harris S (2005) A quantitative analysis of the abundance and demography of European hares Lepus europaeus in relation to habitat type, intensity of agriculture and climate. Mamm Rev 35:1-24. doi:10.1111/j.1365-2907.2005.00057.x

Spagnesi M (2002) Silvilago, Sylvilagus floridanus. In: Spagnesi M, De Marinis AM (eds) Mammiferi d'Italia. Quaderni di Conservazione della Natura. Ministero Ambiente-Istituto Nazionale della fauna Selvatica, Bologna, pp 144-146

Swihart KR (1986) Home range-Body mass allometry in rabbits and hares (Leporidae). Acta Theriol 31:139-148

Swihart RK, Yahner RH (1982) Habitat features influencing use of farmstead shelterbelts by Eastern cottontail (Sylvilagus floridanus). Am Midl Nat 107:411-414. doi:10.2307/2425395

Swihart RK, Yahner RH (1984) Winter use of insular habitat patches by the Eastern cottontail. Acta Theriol 29:45-56

Tapper S, Barnes RFW (1986) Influence of farming practice on the ecology of the Brown hare (Lepus europaeus). J Appl Ecol 23:39-52. doi:10.2307/2403079

Vance DR (1976) Changes in land use and wildlife populations in southeastern Illinois. Wildl Soc Bul 4:11-15

Vaughan N, Lucas E, Harris S, White PCL (2003) Habitat associations of European hares Lepus europaeus in England and Wales: implications for farmland management. J Appl Ecol 40:163-175. doi:10.1046/j.1365-2664.2003.00784.x

Vidus Rosin A, Gilio N, Meriggi A (2008) Introduced Lagomorphs as a threat to "native" Lagomorphs: the case of the Eastern cottontail (Sylvilagus floridanus) in northern Italy. In: Alves PC, Ferrand N, Hacklander K (eds) Lagomorph biology. Evolution, ecology and conservation. Springer, Eidenberg, pp $153-165$ 